\title{
15. Divergent Industrial Water Withdrawal and Energy Consumption Trends in China: A decomposition and sectoral analysis
}

\section{Can Wang and Xinzhu Zheng ${ }^{1}$}

\section{Introduction}

Water and energy are indispensable inputs to modern economies. Currently in China, however, these are both under threat. China's per capita quantity of fresh water is only one-quarter of the global average. The fact those resources are spatially distributed unevenly across the country exacerbates the shortage problem, especially in arid and densely populated parts of northern China. Ominously, at the same time, China faces an energy crisis relating to the dominance of coal in the energy consumption structure and high external energy dependence in general.

From 2000 to 2014, when national water use declined at an annual rate of 0.8 per cent, energy consumption rose at an annual rate of 8.1 per cent. Generally, however, these two variables move in the same direction and show a roughly linear relationship (Figure 15.1).

Changes in water use and energy consumption are sensitive to some common driving factors. Rapid economic growth and population increase will increase demand for water and energy, while technological improvement can curb the increase. Simultaneously, structural adjustment of production will effect water use and energy consumption. In turn, changes in water use and energy consumption will interact with one another.

1 This research was funded jointly by the National Natural Science Foundation of China (No. 71273153 and No. 71525007) and Tsinghua-Rio Tinto Research Center for Resources, Energy and Sustainable Development. 


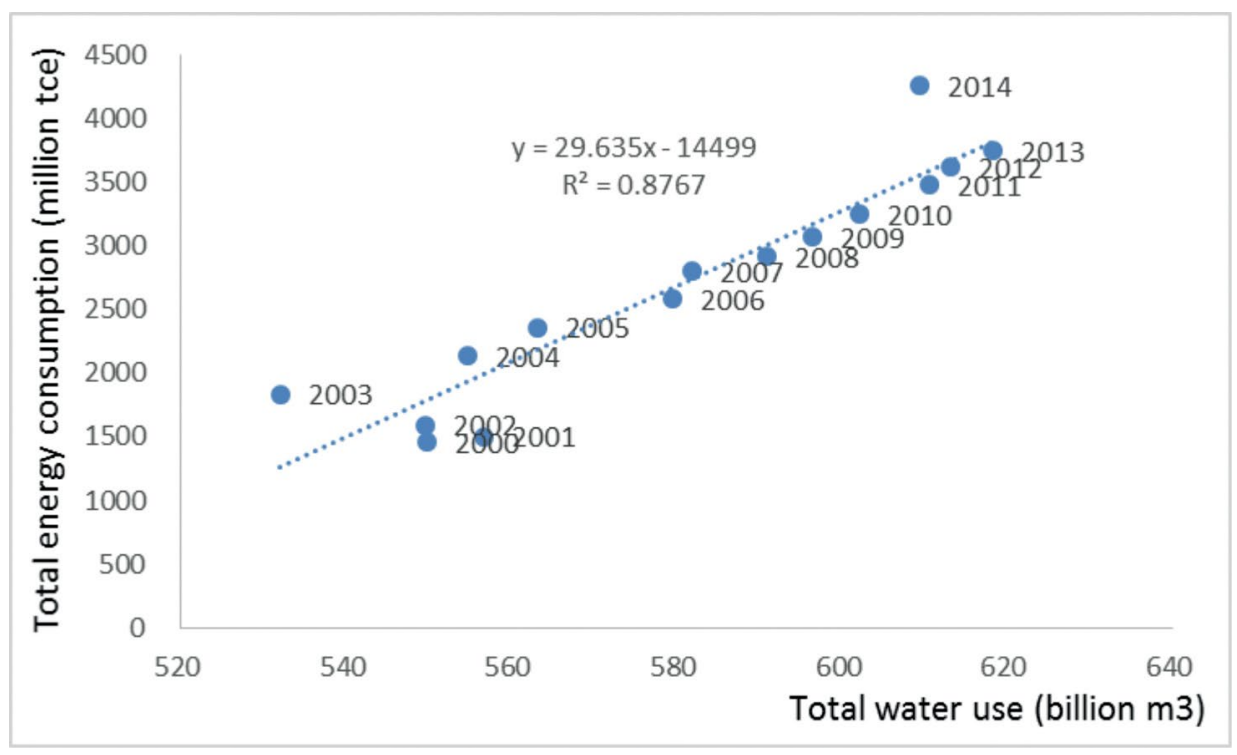

Figure 15.1 Relationships between national water use and energy consumption, 2000-14

Source: Authors' work drawn from MWR (2002-14), NBS (2014b).

Sustainable development requires concurrent management of water and energy resources. Effective control of both requires understanding of the contributions of the common driving factors that produce changes in water use and energy consumption. Studies have explored the effects of these driving factors on energy consumption or on water use. To our knowledge, however, few studies have reviewed and explained changes in water use and energy consumption together, towards the goal of identifying the correlations between these two indicators. This study therefore conducts an investigation into these driving factors, with the main focus being a quantitative comparison of how they contribute to water use and energy consumption simultaneously, and an exploration of the interactions to facilitate integrated water and energy management.

Specifically, we investigate changes in freshwater use and energy consumption across 36 industrial sectors in China. The time frame for the analysis is 2007-12, and this is further divided into two periods: 2002-07 and 2007-12. The latter period serves to distinguish the influence of the Global Financial Crisis (GFC) of 2008. Decomposition methods are used to analyse the drivers of economic growth, population growth, structural adjustment and resource efficiency. Moreover, a deeper analysis of the contribution of individual industrial sectors to these drivers is quantitatively evaluated. The results of that decomposition analysis demonstrate the importance of understanding the interrelated factors that drive change in freshwater use and energy consumption. Future policy in this area should heed the need for integrated water and energy management. 
It is noted that withdrawal and consumption are two aspects of water usage, and this study focuses on the former. According to the United States Geological Survey, 'withdrawal' is defined as the amount of water removed from the ground or diverted from a surface water source for use, while 'consumption' refers to the part of water withdrawn that is lost to evaporation or transpiration, incorporated into products or crops or otherwise removed from the immediate water environment (Kenny et al. 2009). The remainder of this chapter is organised as follows: section two provides a literature review on related decomposition analyses; section three introduces the methodology and data sources for the analysis; section four presents the decomposition results of industrial water withdrawal and energy consumption, including the contributions of individual industrial sectors to the driving factors; while section five concludes with the main findings of this study and offers policy recommendations.

\section{Literature review}

The focus of a recent proliferation of studies has been on the sources of change in energy consumption (Ma 2014), energy intensity (Zeng et al. 2014), carbon dioxide emissions (Zhang and Da 2015; Jiang et al. 2015), carbon dioxide intensity (Liu et al. 2015) and emissions of air pollutants (Guan et al. 2014; Liu and Wang 2013; He 2010). The samples for such studies are global (for example, Lan et al. 2016; Peters and Hertwich 2008), national (for example, Cansino et al. 2016; Feng et al. 2015) and regional (for example, Kang et al. 2014; Lu et al. 2015). Zeng et al. (2014) quantitatively investigated the changing contribution of five driving factors to China's energy intensity fluctuation during 1997-2007. Feng et al. (2015) evaluated the driving factors affecting the decline of carbon dioxide emissions from fossil fuels during 2007-13 in the United States. They found that economic recession was the dominant driver of the decline, rather than the shift from coal to natural gas. Ma (2014) explored the driving factors of a country's changing energy consumption at the multi-fuel, multi-sector and multi-region level. Additional studies have paid attention to the decomposition analysis of interregional embodied carbon flows. Jiang et al. (2015), for example, focused on the virtual carbon flows among eight regions in China and found that trade balance and energy intensity are determining factors.

As China is the largest manufacturer in the world and its industry is energy intensive, large volumes of studies have used decomposition analysis to study the related industrial energy consumption and carbon dioxide emissions. Zha et al. (2009) used a sample comprising 36 industry subsectors in China to investigate what specific factors drive energy intensity in the country. They also provided the contribution degree of subsectors to the structure and intensity effects during 1993-2003. Hasanbeigi et al. (2013) provided retrospective and 
prospective decomposition analyses of energy use in the Chinese manufacturing sector. Zhao et al. (2014) compare the energy consumption and energy intensity of Japanese and Chinese manufacturing industries at the sectoral level. Wu and Huo (2014) analyse the effectiveness of energy conservation policies in China through the study of energy efficiency impacts in the industrial and transport sectors. Liu et al. (2007) have analysed the change in China's industrial carbon dioxide emissions over the period 1998-2005 using the logarithmic mean Divisia index (LMDI) method. Ouyang and Lin (2015) provided a similar study in the period 1991-2010. Yan and Fang (2015) focus on energy-related carbon dioxide emissions from Chinese manufacturing for the period 1993-2011 and explore the mitigation potential based on scenario analyses. Liu et al. (2015) analyse the change in carbon intensity in China's industrial sector over the period 1996-2012 using the Divisia index decomposition method, and also identified the contribution of individual subsectors. Apart from industrial energy consumption and carbon dioxide emissions, there are also some studies analysing China's industrial air pollutant emissions. For example, Fujii et al. (2013) analyse the changes in emissions of air pollutants in 10 Chinese industrial sectors from 1998 to 2009, and illustrate the impact of the elimination policy on air pollution management.

Compared with studies of energy use and related environmental impacts, those investigating factors contributing to change in water use are comparatively few. Duarte et al. (2014) decomposed global water use over the entire twentieth century to project future water use trends. Zhang et al. (2012) focused on Beijing's water challenges and conducted a decomposition analysis for both the internal and the external water footprints over the period 1997-2007. The results shed light on strategies to combat the challenge.

Few studies simultaneously explore two or more indicators. One exception is Kopidou et al.'s (2016) study, which explored common trends in and drivers of carbon dioxide emissions and employment. To our understanding, this literature review implies that our study is an original one, as it compares the effects of driving factors on both industrial energy consumption and water withdrawal. As in the case of the studies mentioned, the decomposition results of this study are intended to review past performance to facilitate a future integrated management approach to water and energy resources. 


\section{Methodology and data}

\section{Driving factors}

The contributions of four driving factors-economic scale, structural adjustment, resource intensity and population growth - to water withdrawal and energy consumption are explored in this study. This follows from the logic that economic and population growth can stimulate both increased freshwater withdrawal and energy consumption. Structural shifts in production are seen as an important pathway for tackling environmental and energy issues in China (State Council of China 2011). In fact, given the scale of the dual challenge of water and energy conservation, retuning the industrial structure is unavoidable. A structural shift to energy-efficient but water-intensive sectors is expected to alleviate the energy crisis and related air pollution, but will put greater pressure on water resources. Resource intensity is another important factor driving changes in water withdrawal and energy consumption. Resource intensity is defined as the water withdrawal or energy consumption per unit of value added in each industrial sector.

\section{Methodology}

There are two main methods for undertaking decomposition analysis at the sectoral level: index decomposition analysis (IDA) and structural decomposition analysis (SDA). The similarities and differences between IDA and SDA were introduced in the literature by Hoekstra and van den Bergh (2003) and Su and Ang (2012). The decomposition analysis adopted in this study is the LMDI method (Ang and Zhang 2000; Ang 2015) - a frequently used IDA method.

In the LMDI model, industrial freshwater withdrawal can be given by Equation 15.1.

\section{Equation 15.1}

$$
W=\sum_{i} W_{i}=\sum_{i} f_{i} s_{i} e P=\sum_{i} \frac{W_{i}}{Q_{i}} \frac{Q_{i}}{Q} \frac{Q}{P} P
$$

In Equation 15.1, $W$ is total industrial freshwater withdrawal; $W_{i}$ is the freshwater withdrawal of sector $i ; f_{i}$ is the water intensity of sector $i$, defined as the ratio of freshwater withdrawal in sector $i\left(W_{i}\right)$ to its value added $\left(Q_{i}\right) ; s_{i}$ is the share of sector $i$ in total industrial output, defined as the ratio of value added in 
sector $i\left(Q_{i}\right)$ to the total industrial value added $(Q)$; $e$ is the industrial value added per capita, defined as the ratio of total industrial value added $(Q)$ to national population $(P)$; and $P$ is national population.

The changes in industrial freshwater withdrawal $(\Delta W)$ from the base year, 0 , to year $t$ are decomposed into the changes driven by four effects: 1) the water intensity effect $(\Delta f) ; 2)$ the production structure effect $(\Delta s)$; 3) the economic scale effect $(\Delta e)$; and 4$)$ the population effect $(\Delta P)$ (Equation 15.2).

\section{Equation 15.2}

$$
\Delta W=W_{t}-W_{0}=\Delta f+\Delta s+\Delta e+\Delta P
$$

The changes caused by each driving factor can be calculated by Equation 15.3.

\section{Equation 15.3}

$$
\begin{aligned}
\Delta f & =\sum_{i} L\left(W_{i}^{t}, W_{i}^{0}\right) \times \ln \left(f_{i}^{t} / f_{i}^{0}\right) \\
\Delta s & =\sum_{i}^{i} L\left(W_{i}^{t}, W_{i}^{0}\right) \times \ln \left(s_{i}^{t} / s_{i}^{0}\right) \\
\Delta e & =\sum_{i}^{i} L\left(W_{i}^{t}, W_{i}^{0}\right) \times \ln \left(e^{t} / e^{0}\right) \\
\Delta P & =\sum_{i} L\left(W_{i}^{t}, W_{i}^{0}\right) \times \ln \left(P^{t} / P^{0}\right)
\end{aligned}
$$

In this, the logarithmic mean of total industrial water withdrawal is given by Equation 15.4.

\section{Equation 15.4}

$$
L\left(W_{i}^{t}, W_{i}^{0}\right)=\left(W_{i}^{t}, W_{i}^{0}\right) /\left(\ln W_{i}^{t}-\ln W_{i}^{0}\right)
$$

The decomposition method for industrial energy consumption is similar. Industrial energy consumption can be given by Equation 15.5.

\section{Equation 15.5}

$$
E=\sum_{i} E_{i}=\sum_{i} f^{\prime}{ }_{i} s_{i} e P=\sum_{i} \frac{E_{i}}{Q_{i}} \frac{Q_{i}}{Q} \frac{Q}{P} P
$$


In this equation, $E$ is total industrial energy consumption; $E_{i}$ is the energy consumption of sector $i ; f_{i}^{\prime}$ is the energy intensity of sector $i$, defined as the ratio of energy consumption in sector $i\left(E_{i}\right)$ to its value added $\left(Q_{i}\right) ; s_{i}$ is the share of sector $i$ in total industrial output, defined as the ratio of value added in sector $i\left(Q_{i}\right)$ to total industrial value added $(Q) ; e$ is industrial value added per capita, defined as the ratio of total industrial value added $(Q)$ to national population $(P)$; and $P$ is national population.

Changes in industrial energy consumption $(\Delta E)$ from the base year, 0 , to year $t$ are decomposed into the changes driven by four factors: 1) the water intensity effect $(\Delta f) ; 2)$ the production structure effect $(\Delta s)$; 3) the economic scale effect $(\Delta e)$; and 4$)$ the population effect $\left(\Delta P^{\prime}\right)$ (Equation 15.6).

\section{Equation 15.6}

$$
\Delta E=E_{t}-E_{0}=\Delta f^{\prime}+\Delta s^{\prime}+\Delta e^{\prime}+\Delta P^{\prime}
$$

The changes caused by each driving factor can be calculated by Equation 15.7.

\section{Equation 15.7}

$$
\begin{aligned}
\Delta f^{\prime} & =\sum_{i} L\left(E_{i}^{t}, E_{i}^{0}\right) \times \ln \left(f_{i}^{\prime t} / f_{i}^{\prime 0}\right) \\
\Delta s^{\prime} & =\sum_{i} L\left(E_{i}^{t}, E_{i}^{0}\right) \times \ln \left(s_{i}^{t} / s_{i}^{0}\right) \\
\Delta e^{\prime} & =\sum_{i}^{i} L\left(E_{i}^{t}, E_{i}^{0}\right) \times \ln \left(e^{t} / e^{0}\right) \\
\Delta P^{\prime} & =\sum_{i} L\left(E_{i}^{t}, E_{i}^{0}\right) \times \ln \left(P^{t} / P^{0}\right)
\end{aligned}
$$

The logarithmic mean of total industrial water withdrawal is given by Equation 15.8.

\section{Equation 15.8}

$$
L\left(E_{i}^{t}, E_{i}^{0}\right)=\left(E_{i}^{t}, E_{i}^{0}\right) /\left(\ln E_{i}^{t}-\ln E_{i}^{0}\right)
$$

\section{Data sources}

This study's focus is on 36 secondary industrial sectors in China, covering energy production and supply and manufacturing. The water production and supply sector is excluded from the discussion due to the data limitations. Data on the value added for each sector in 2002 and 2007 come from the annual 
China industrial economy statistical yearbook (NBS various years). The data for value added for each sector in 2012 come from China's Input-output table for 2012 (NBS 2012). The current industrial value added was deflated into 2002 constant prices. The energy consumption data were cited from the 2014 China energy statistical yearbook (NBS 2014a). Data for freshwater withdrawal in industrial sectors were taken from the Annual statistical report on the environment in China (MEP various years). The computational problems with the zero values of the variables given in the logarithmic form are overcome by replacing the zero values with a small positive number, referring to Ang and Choi's (1997) study. Convergence results are obtained as the positive number approaches zero.

\section{Results and discussion}

\section{Declining water withdrawal and growing energy consumption}

Over the period 2002-12, industrial water withdrawal in China decreased by 27.5 per cent (MEP various years). Using the methodology outlined above, we calculate that, driven by economic growth, freshwater withdrawals (yellow bars in Figure 15.2) in 2002-07 increased by 60.9 per cent. Population growth (purple bars in Figure 15.2) further pushed up freshwater withdrawals, by 2.7 per cent; however, the overall level of industrial water withdrawals in the period decreased, by 6.1 per cent. This is a result of changes in water intensity (-58.6 per cent) and in production structure ( -11.1 per cent). A similar situation occurred between 2007 and 2012. The decreases in water intensity and production structure offset the increases caused by economic growth and population growth and led to declining water withdrawals.

Unlike the declining trend for industrial freshwater withdrawals, industrial energy consumption in China increased significantly over the same period (Figure 15.3). Our calculations identify a sharp acceleration of 137.9 per cent in industrial energy consumption across 2002-12. The only factor helping to curb increasing industrial energy consumption was falling energy intensity. There were different but related trends around the GFC of 2008. In the five years before the GFC, industrial energy consumption increased by 88.5 per cent. The downward influence of energy intensity ( -18.8 per cent) was overwhelmed by the upward influence of changes in economic growth $(+88.3$ per cent), population growth $(+3.9$ per cent) and production structure $(+14.1$ per cent). In the five years after the onset of the GFC, the more substantial effect of the decrease in energy intensity ( -73.5 per cent) slowed the growth of industrial energy consumption. However, the downward influence of energy intensity still cannot offset the upward influence of economic growth (+87.9 per cent), population growth $(+2.7$ per cent) and production structure adjustment ( +9 per cent). 


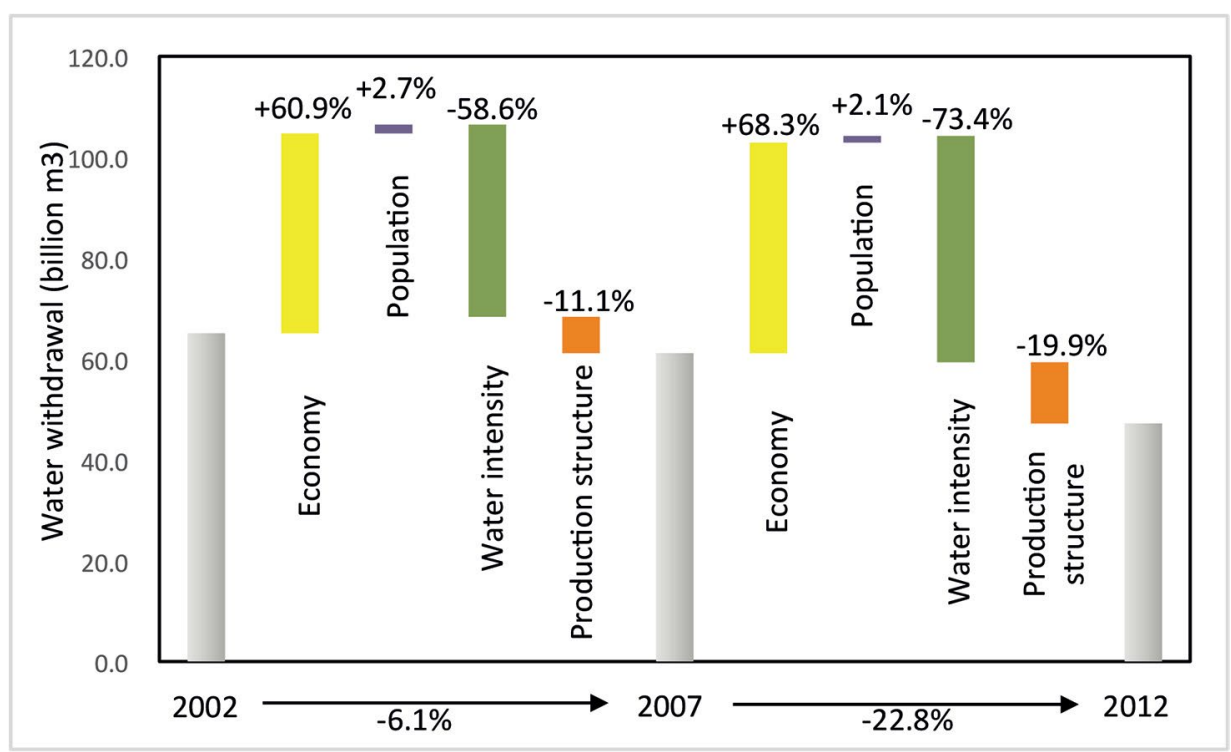

Figure 15.2 Decomposition results for changes in industrial freshwater withdrawals, 2002-12

Source: Authors' work.

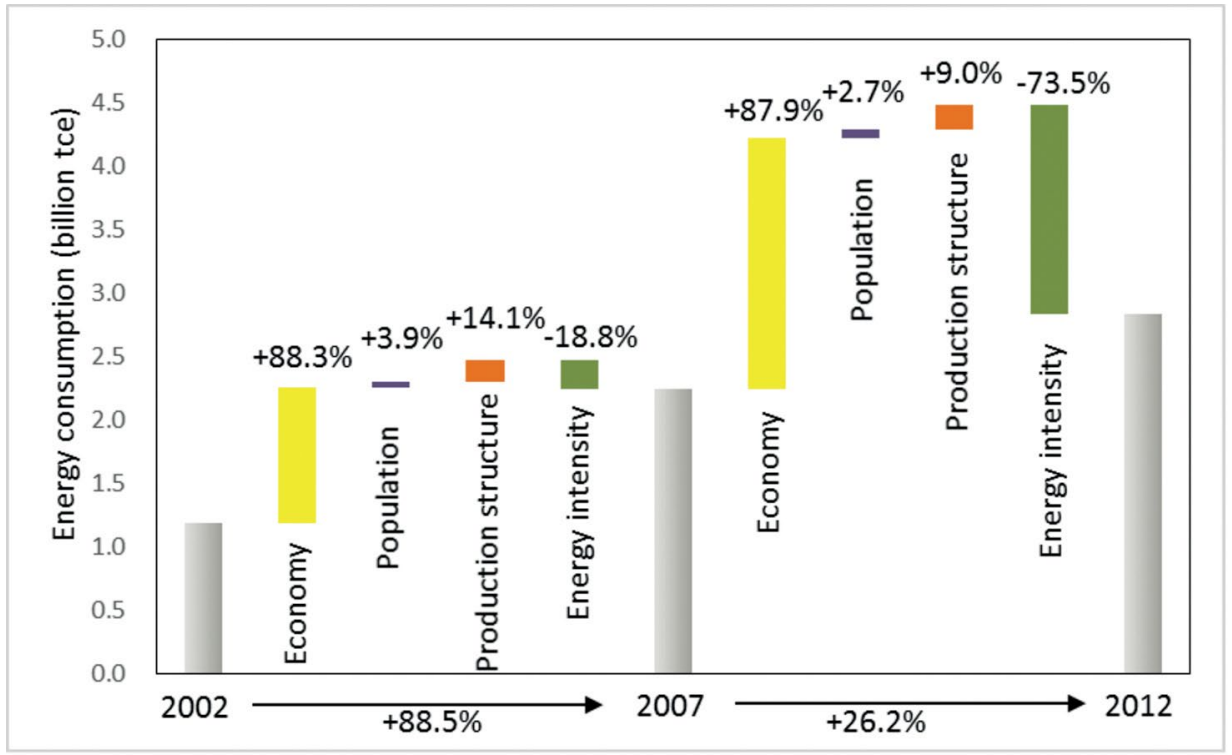

Figure 15.3 Decomposition results for changes in industrial energy consumption, 2002-12

Source: Authors' work. 
Comparison of the driving factors of these two indicators identifies several noteworthy findings. In the period 2002-12, economic development served as the dominant factor driving the increase in both industrial freshwater withdrawal and energy consumption. Falls in intensity were the primary driver curbing the growth of industrial freshwater withdrawals and energy consumption. Importantly, the reason for the divergent trends between water withdrawal and energy consumption is that the improvement in water efficiency exerted more influence than the improvement in energy efficiency over the past decade. The reduction effect of improvements in water efficiency exceeded the promotion effect of economic growth and so decreased overall freshwater withdrawals. This optimistic situation did not, however, emerge for energy consumption. Instead, the downward effect of declining energy intensity was insufficient to offset the increasing effect caused by economic growth-due mainly to the energy intensiveness of industry in China.

\section{Mutually related economic growth and resource efficiency}

These results illustrate that the water efficiency effect overwhelmed the economic growth effect, producing a decline in water withdrawals, while the opposite happened to industrial energy consumption. Although the prevailing patterns in changes to water withdrawal and energy consumption were divergent, there is a common theme in that the two dominant driving factors-economic scale and resource intensity - interacted mutually in terms of the degree of contribution at the subsector level. The degrees of contribution of individual industrial sectors to each driving factor are provided in Figure 15.4.

Across the entire sample period, the increase in energy consumption caused by economic growth occurred mainly in four sectors: smelting and pressing of ferrous metals, non-metal mineral production, chemical production and the smelting and pressing of nonferrous metals. These sectors also contributed significantly to the decrease in energy intensity (26.6 per cent, 13.7 per cent, 13.7 per cent and 10.2 per cent, respectively) (Figure 15.4a). The increase of freshwater withdrawals that was caused mainly by economic growth arose mainly from the electricity/heating supply sector. This sector is also the main contributor to the falling water intensity of production (56.1 per cent). That is, across the period 2002-12, the sectors whose production scales accelerated significantly also demonstrated the most obvious improvement in energy or water intensity. These sectoral decomposition results illustrate that those sectors experiencing economic growth made the most effort to improve resource efficiency (Figure 15.4b). This finding is consistent with Kopidou et al.'s (2016) study, which explored the common trends and drivers of carbon dioxide emissions and employment. 


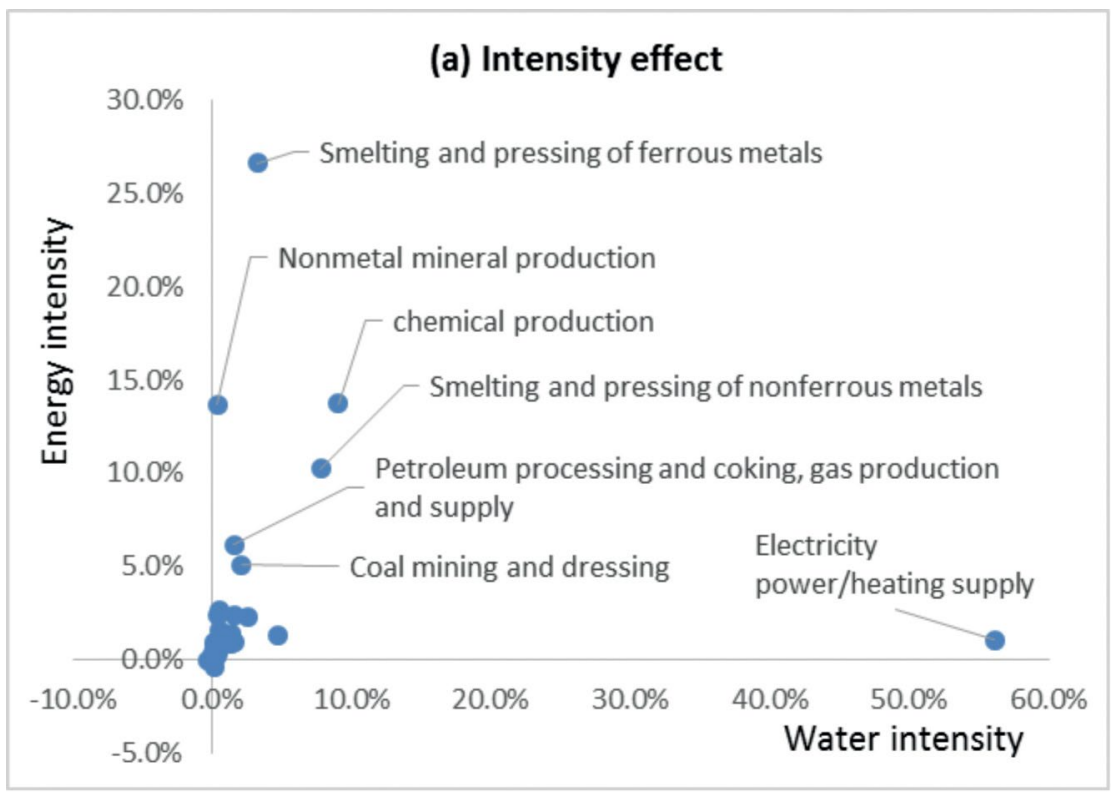

Figure 15.4a Degree of contribution of individual industrial sectors to the resource intensity effect

Source: Authors' work.

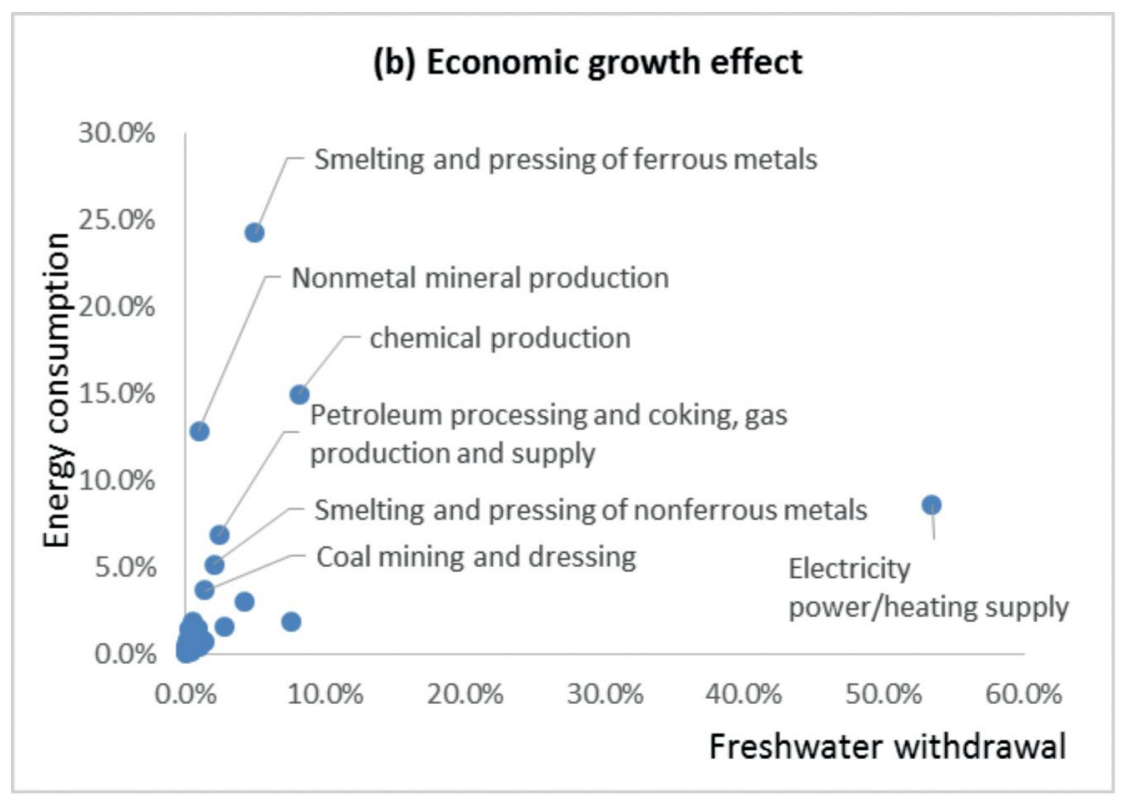

Figure 15.4b Degree of contribution of individual industrial sectors to the economic growth effect

Source: Authors' work. 


\section{Divergence of structural shifts in water and energy use}

Divergence between the driving effects of production structure on freshwater withdrawal and energy consumption was observed in the period 2002-12 (Figures 15.2 and 15.3) in this study. Increases in industrial freshwater withdrawals were inhibited by adjustment of production structure, while industrial energy consumption was increased.

The reason for this divergence is illustrated by further decomposition results at the sectoral scale (Table 15.1). For structural adjustment, the share of 17 industrial sectors in total production fell, including in selective water-intensive industries, including electricity/heating supply, paper printing, textile manufacturing and beverage manufacturing. At the same time, the share of the other 19 sectors increased. The increasing proportion of selected energyintensive industries - such as smelting and pressing of ferrous metals, smelting and pressing of nonferrous metals and coalmining and dressing - is the main contributor to the expansion of industrial energy consumption and freshwater withdrawal. The fact that industrial production turned out to be more water efficient but remained energy intensive suggests China should continuously adjust its industrial structure.

\section{Exploration of selected industrial sectors}

In this study, selected industrial sectors are highlighted as the biggest contributors to the increase of both freshwater withdrawal and energy consumption. These include the smelting and pressing of ferrous metals sector and the non-metal mineral production sector. Moreover, for the electricity/heating supply and the smelting and pressing of nonferrous metals sectors, although their energy consumption increased significantly, they were the primary contributors to the decrease of industrial freshwater withdrawals. Based on the multisectoral decomposition results for industrial freshwater withdrawal and energy consumption (Table 15.1), this section will provide detailed analysis of the contributions of highlighted subsectors. 


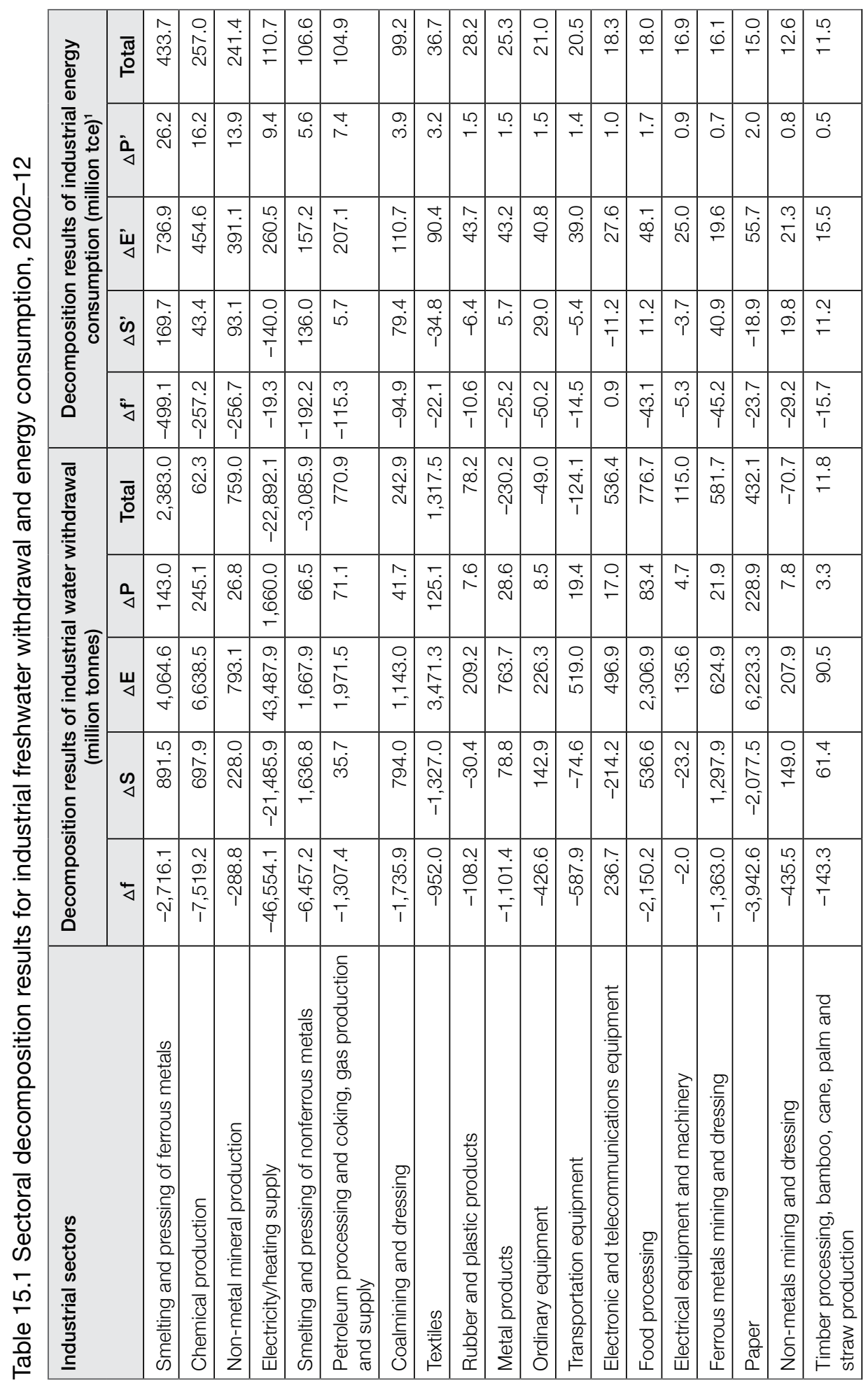




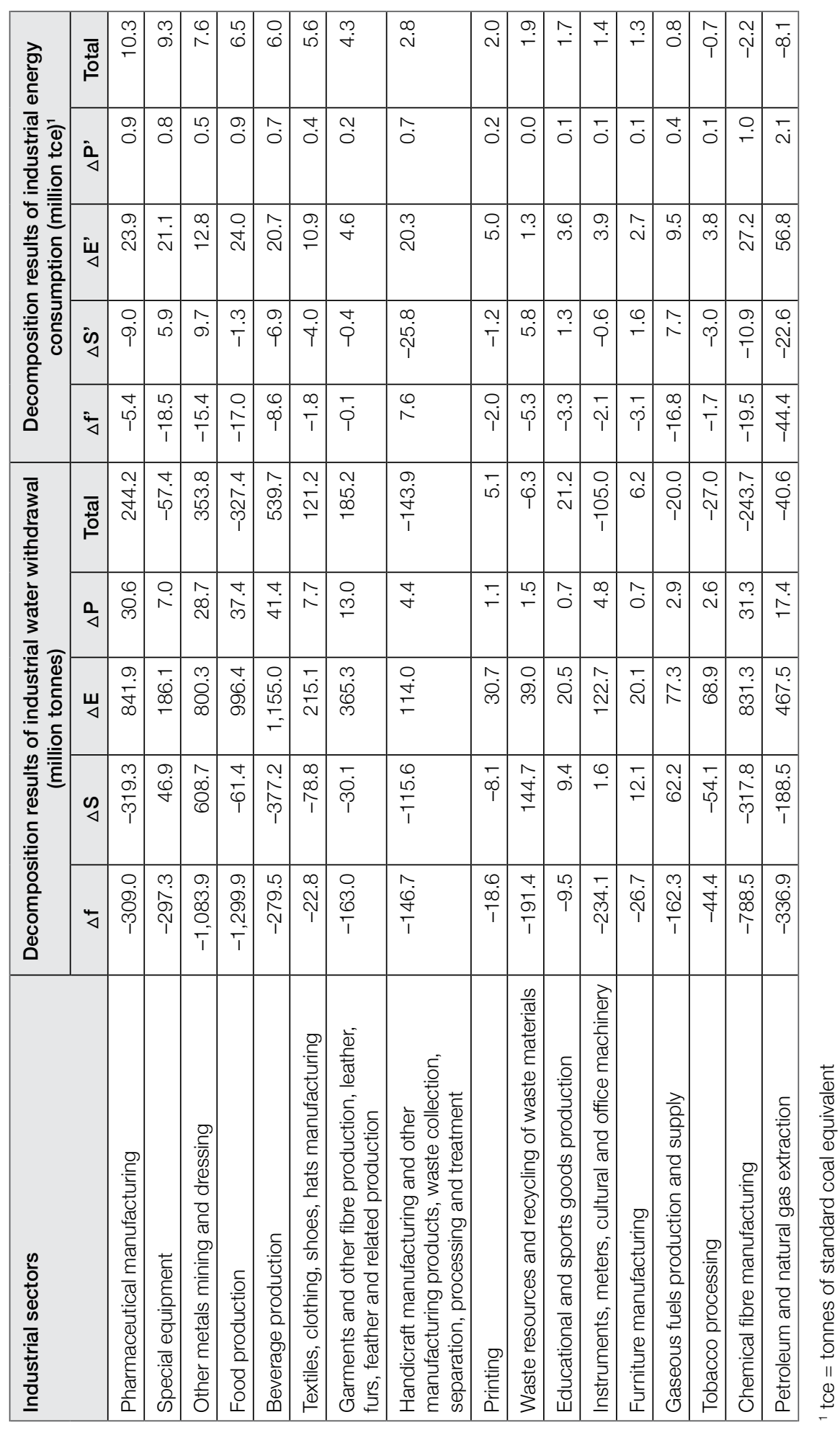




\section{Electricity/heating supply sector}

From 2002 to 2012, the electricity/heating supply sector contributed the most to the decrease in industrial freshwater withdrawals. The cumulative decrease in freshwater withdrawals by this sector over the period was 22.9 billion cubic metres. Economic growth in the sector initially increased freshwater withdrawals by 43.5 billion cu $\mathrm{m}$, but water intensity improvements served to reduce the withdrawals dramatically $(\Delta \mathrm{f}=-46.6$ billion $\mathrm{cu} \mathrm{m})$. Although the economic effect made a substantial additional contribution to the increase of freshwater withdrawals in the electricity/heating supply sector, improvements in efficiency offset this upward influence and served to decrease freshwater withdrawals. It was also observed that the electricity/heating supply sector made the greatest contribution to the adverse effects of production structure on energy consumption. Although economic growth also significantly increased energy consumption $\left(\Delta \mathrm{E}^{\prime}=+62.5\right.$ million tonnes of standard coal equivalent, or tce), the curbing effect of improved energy intensity could not compensate for the otherwise increased consumption over 2002-12. Thus, energy consumption in the electricity/heating supply sector increased by 11.5 million tce in that period.

\section{Smelting and pressing of ferrous metals}

In total, across all industries and over the period 2002-12, the smelting and pressing of ferrous metals sector contributed the most to increases in both industrial energy consumption and industrial water withdrawal. Significant increases in both production scale and industrial proportion, alongside only a marginal fall in energy intensity, caused a 338.33 million tce increase in energy consumption in the sector. At the same time, all three of the driving factors studied herein, including water intensity, had additive effects on the increase of water withdrawals, leading to an increase in withdrawals of 3.3 billion tonnes over 2002-07. Over the second five-year interval, however, the energy and water intensities of this sector improved significantly. The energy efficiency improvement in the iron and steel sector in that period largely compensated for the additive influence of economic growth, meaning that the overall increase in energy consumption was only 95.4 million tce. These considerable efficiency improvements were also seen in relation to freshwater withdrawal in this sector. During 2002-07, increased water intensity in the iron and steel sector served to increase freshwater withdrawals, while during 2007-12, water intensity decreased dramatically and inhibited freshwater withdrawals.

\section{Other industrial sectors}

Aside from the considerable increase in energy consumption in the smelting and pressing of ferrous metals sector, large energy consumption growth also occurred in the following sectors: coalmining and dressing, smelting and 
pressing of nonferrous metals, chemical production and petroleum processing and coking, gas production and supply. Energy consumption in these sectors was, however, curbed somewhat by the energy intensity effect. But energy efficiency improvements were not enough to offset the additive effect of economic growth. The energy intensity effect improved in the second interval of our study, but the inhibitive effect on energy consumption was limited. Meanwhile, freshwater withdrawals in these sectors did not demonstrate obvious changes, because water efficiency improvement almost offset the effect of economic growth.

\section{Conclusion}

This study sought to understand the drivers of water and energy consumption in China towards facilitating the evolution of integrated water and energy management. Focusing on 36 secondary industrial sectors, and covering energy production and supply and manufacturing, the study explored the driving factors behind recent changes in industrial water withdrawal and energy consumption in China. A decomposition analysis using the LMDI method was adopted and applied to the period 2002-12, which was itself subdivided into two five-year periods that pivot around the potential impact of the GFC in 2008. The main findings are as follows:

1. Declining water withdrawal and growing energy consumption in Chinese industrial sectors were observed over the period 2002-12. Decomposing these trends identified that economic development served as the dominant additive factor driving the increase of both industrial freshwater withdrawal and industrial energy consumption. Declining energy intensity of production was the primary driver helping to curb that rate of growth. The different trends in water withdrawal and energy consumption are explained by the fact that in the past decade water efficiency improvement has exerted a more obvious effect than energy efficiency improvement. The reduction effect of water efficiency improvement exceeded the promotion effect of economic growth, serving to reduce overall freshwater withdrawals. Such an optimistic situation did not emerge vis-a-vis energy consumption.

2. Although the prevailing pattern of change in water withdrawal and energy consumption diverged, the common factors of economic scale and resource intensity interacted with one another. Sectors experiencing economic growth were more active in improving resource efficiency. Over the entire period, the increase in energy consumption caused by economic growth occurred mainly in four sectors: smelting and pressing of ferrous metals; non-metal mineral production; chemical production; and smelting and pressing of nonferrous metals. These four sectors also contributed significantly to the decrease in energy intensity of production (26.6 per cent, 13.7 per cent, 
13.7 per cent and 10.2 per cent, respectively). In parallel, the sectors in which there was an increase in freshwater withdrawal induced by economic growth were mainly those related to the electricity/heating supply sector, which is also the main contributor to falling water intensity of production (56.1 per cent).

3. Divergence between the driving effects of production structure on freshwater withdrawal and energy consumption was observed during the sampling period. The fact that industrial production was found to be increasingly water efficient but also highly energy intensive suggests China should continue to adjust its industrial structure.

4. Some industrial sectors are highlighted due to the significance of their contributions to changes in industrial water withdrawal and industrial energy consumption. For example, the smelting and pressing of ferrous metals sector contributed the most to the increase in both industrial energy consumption and industrial water withdrawal. The electricity/heating supply sector played a significant role in curbing the intensity of industrial water withdrawal in China.

Despite the interaction identified herein between water use and energy consumption in China, at present national policies for water and energy are determined separately. Given the importance of sustainable development and, in particular, the fragility of China's highly degraded water supplies, this chapter addresses the need to better integrate water and energy resource management in the country. Future research could further support the implementation of integrated management by exploring the trade-offs and synergies of various policies and technological alternatives.

\section{References}

Ang, B. W. (2015), LMDI decomposition approach: A guide for implementation, Energy Policy, 86: 233-238.

Ang, B. W. and Choi, K. H. (1997), Decomposition of aggregate energy and gas emission intensities for industry: A refined Divisia index method, The Energy Journal, 18(3): 59-73.

Ang, B. W. and Zhang, F. Q. (2000), A survey of index decomposition analysis in energy and environmental studies, Energy, 25(12): 1149-1176.

Cansino, J. M., Román, R. and Ordóñez, M. (2016), Main drivers of changes in $\mathrm{CO}_{2}$ emissions in the Spanish economy: A structural decomposition analysis, Energy Policy, 89: 150-159. 
Duarte, R., Pinilla, V. and Serrano, A. (2014), Looking backward to look forward: Water use and economic growth from a long-term perspective, Applied Economics, 46(2): 212-224.

Feng, K., Davis, S. J., Sun, L. and Hubacek, K. (2015), Drivers of the US $\mathrm{CO}_{2}$ emissions 1997-2013, Nature Communications, 6: 7714.

Fujii, H., Managi, S. and Kaneko, S. (2013), Decomposition analysis of air pollution abatement in China: Empirical study for ten industrial sectors from 1998 to 2009, Journal of Cleaner Production, 59: 22-31.

Guan, D., Su, X., Zhang, Q., Peters, G. P., Liu, Z., Lei, Y. and He, K. (2014), The socioeconomic drivers of China's primary PM2.5 emissions, Environmental Research Letters, 9(2): 024010.

Hasanbeigi, A., Price, L., Fino-Chen, C., Lu, H. and Ke, J. (2013), Retrospective and prospective decomposition analysis of Chinese manufacturing energy use and policy implications, Energy Policy, 63: 562-574.

$\mathrm{He}, \mathrm{J}$. (2010), What is the role of openness for China's aggregate industrial $\mathrm{SO}_{2}$ emission? A structural analysis based on the Divisia decomposition method, Ecological Economics, 69(4), 868-886.

Hoekstra, R., and van den Bergh, J. C. (2003), Comparing structural decomposition analysis and index. Energy economics, 25(1): 39-64.

Jiang, Y., Cai, W., Wan, L. and Wang, C. (2015), An index decomposition analysis of China's interregional embodied carbon flows, Journal of Cleaner Production, 88: 289-296.

Kang, J., Zhao, T., Liu, N., Zhang, X., Xu, X. and Lin, T. (2014), A multi-sectoral decomposition analysis of city-level greenhouse gas emissions: Case study of Tianjin, China, Energy, 68: 562-571.

Kenny, J. F., Barber, N. L., Hutson, S. S., Linsey, K. S., Lovelace, J. K. and Maupin, M. A. (2009), Estimated use of water in the United States in 2005, United States Geological Survey Circular: 1344.

Kopidou, D., Tsakanikas, A. and Diakoulaki, D. (2016), Common trends and drivers of $\mathrm{CO}_{2}$ emissions and employment: A decomposition analysis in the industrial sector of selected European Union countries, Journal of Cleaner Production, 112: 4159-4172.

Lan, J., Malik, A., Lenzen, M., McBain, D. and Kanemoto, K. (2016), A structural decomposition analysis of global energy footprints, Applied Energy, 163: 436-451. 
Liu, L., Fan, Y., Wu, G. and Wei, Y. (2007), Using LMDI method to analyze the change of China's industrial $\mathrm{CO}_{2}$ emissions from final fuel use: An empirical analysis, Energy Policy, 35(11): 5892-5900.

Liu, N., Ma, Z. and Kang, J. (2015), Changes in carbon intensity in China's industrial sector: Decomposition and attribution analysis, Energy Policy, 87: $28-38$.

Liu, Q. and Wang, Q. (2013), Pathways to $\mathrm{SO}_{2}$ emissions reduction in China for 1995-2010: Based on decomposition analysis, Environmental Science \& Policy, 33: 405-415.

Lu, Q., Yang, H., Huang, X., Chuai, X. and Wu, C. (2015), Multi-sectoral decomposition in decoupling industrial growth from carbon emissions in the developed Jiangsu Province, China, Energy, 82: 414-425.

Ma, C. (2014), A multi-fuel, multi-sector and multi-region approach to index decomposition: An application to China's energy consumption 1995-2010, Energy Economics, 42: 9-16.

Ministry of Environmental Protection (MEP) (various years), Annual statistical report on the environment in China, Beijing: China Environmental Science Press.

Ministry of Water Resources (MWR) (2002-2014), China Water Resources Bulletin, [in Chinese], Beijing: China Waterpower Press.

National Bureau of Statistics (NBS) (various years), China industrial economy statistical yearbook, Beijing: China Statistics Press.

National Bureau of Statistics (NBS) (2012), Input-output table, Beijing: China Statistics Press. Available from: data.stats.gov.cn/ifnormal.htm? $u=/$ files/ html/quickSearch/trcc/trcc01.html\&h=740.

National Bureau of Statistics (NBS) (2014a), China energy statistical yearbook, Beijing: China Statistics Press.

National Bureau of Statistics (NBS) (2014b), China Statistical Yearbook, [in Chinese], Beijing: China Statistics Press.

Ouyang, X. and Lin, B. (2015), An analysis of the driving forces of energyrelated carbon dioxide emissions in China's industrial sector, Renewable and Sustainable Energy Reviews, 45: 838-849.

Peters, G. P. and Hertwich, E. G. (2008), $\mathrm{CO}_{2}$ embodied in international trade with implications for global climate policy, Environmental Science \& Technology, 42(5): 1401-1407. 
State Council of China (2011), Comprehensive work plan for energy conservation and emission reduction during the 'Twelfth Five-Year Plan' period, Beijing: State Council. Available from: gov.cn/zwgk/2011-09/07/content_1941731.htm.

Su, B., and Ang, B. W. (2012), Structural decomposition analysis applied to energy and emissions: some methodological developments. Energy Economics, 34(1): 177-188.

Wu, L. and Huo, H. (2014), Energy efficiency achievements in China's industrial and transport sectors: How do they rate?, Energy Policy, 73: 38-46.

Yan, X. and Fang, Y. (2015), $\mathrm{CO}_{2}$ emissions and mitigation potential of the Chinese manufacturing industry, Journal of Cleaner Production, 103: 759-773.

Zeng, L., Xu, M., Liang, S., Zeng, S. and Zhang, T. (2014), Revisiting drivers of energy intensity in China during 1997-2007: A structural decomposition analysis, Energy Policy, 67: 640-647.

Zha, D., Zhou, D. and Ding, N. (2009), The contribution degree of sub-sectors to structure effect and intensity effects on industry energy intensity in China from 1993 to 2003, Renewable and Sustainable Energy Reviews, 13(4): 895-902.

Zhang, Y. and Da, Y. (2015), The decomposition of energy-related carbon emission and its decoupling with economic growth in China, Renewable and Sustainable Energy Reviews, 41: 1255-1266.

Zhang, Z., Shi, M. and Yang, H. (2012), Understanding Beijing's water challenge: A decomposition analysis of changes in Beijing's water footprint between 1997 and 2007, Environmental Science \& Technology, 46(22): 12373-12380.

Zhao, Y., Ke, J., Ni, C. C., McNeil, M., Khanna, N. Z., Zhou, N., Fridley, D. and Li, Q. (2014), A comparative study of energy consumption and efficiency of Japanese and Chinese manufacturing industry, Energy Policy, 70: 45-56. 
This text is taken from China's New Sources of Economic Growth: Reform, resources and climate change, Volume 1, edited by Ligang Song, Ross Garnaut, Cai Fang \& Lauren Johnston, published 2016 by ANU Press, The Australian National University, Canberra, Australia. 